\title{
Rede de Atenção Psicossocial: qual o lugar da saúde mental?
}

I ' Paulo Henrique Dias Quinderé, 2 Maria Salete Bessa Jorge,

${ }^{3}$ Túlio Batista Franco I

Resumo: A Reforma Sanitária brasileira propiciou maior aplicabilidade das açôes locais, favorecendo o surgimento de experiências exitosas nos diversos setores da saúde. Uma destas foi a criação dos Centros de Atenção Psicossocial (Caps), que subvertem a lógica da hierarquização do sistema de saúde e se organizam agregando os diferentes níveis de atenção à saúde. Objetivou-se discutir as interaçôes estabelecidas entre os níveis de complexidade do sistema de saúde na atenção à saúde mental e compreender a conformação da rede de atenção à saúde mental no município de Sobral-CE. Trata-se de estudo do tipo qualitativo realizado na Rede de Atenção Integral à Saúde Mental desse município. Os resultados demonstraram que os serviços de saúde mental em Sobral convivem com diferentes arranjos em rede, operando por uma diversidade de dispositivos de cuidado o que possibilita a negociação de projetos terapêuticos menos medicalizantes, embora se observe que permanece atenção especial dos trabalhadores quanto à centralidade da administração da medicação. Há grande mobilidade dos trabalhadores na rede, circulando os diversos equipamentos de saúde, o que favorece as conecçôes e fluxos entre equipes na construção das linhas de cuidado. Os fluxos de conexão, considerados como modo de funcionamento das redes rizomáticas, operam na saúde mental por força da ação dos trabalhadores, que tem por base a ideia de que todos são protagonistas no processo de cuidado, e assim, os movimentos são partilhados e articulados entre si.

> Palavras-chave: assistência em saúde mental; serviços comunitários de saúde mental; cuidados integrais de saúde; níveis dos cuidados de saúde.

\author{
1 Psicólogo; doutor em \\ Saúde Coletiva, Universidade \\ Estadual do Ceará. Fortaleza, \\ quinderephd@gmail.com \\ ${ }^{2}$ Doutora em Enfermagem \\ EERP/USP; pós-doutora em \\ Saúde Coletiva; pesquisadora \\ CNPq 1C; docente do Mestrado \\ em Saúde Pública, Universidade \\ Estadual do Ceará. Fortaleza \\ Brasil. Endereço eletrônico: \\ ${ }^{3}$ Professor doutor da \\ Universidade Federal \\ Fluminense. Niterói-RJ, \\ tuliofranco@gmail.com
}




\section{As redes na organização dos serviços de saúde}

Com o advento do Sistema Único de Saúde (SUS), instituído nos anos 1980/90, tema relevante sempre presente na agenda dos gestores e formuladores das políticas de saúde é a constituição de redes assistenciais. O pressuposto é que não há um equipamento ou mesmo equipe de saúde considerado autossuficiente na produção do cuidado. Pela alta complexidade dos problemas de saúde, geralmente envolvendo vários campos de saber, pela interdisciplinaridade inerente às questôes da saúde, e multiplicidade de atores sociais implicados com a gestão e o cuidado, as redes se tornam uma prerrogativa para seu funcionamento, sendo portanto inerentes ao trabalho voltado ao cuidado em saúde. É esta discussão que o presente artigo propõe como contribuição ao rico debate sobre o tema.

Um primeiro movimento importante para a formação de redes se deu com a descentralização da saúde no Brasil, a qual possibilitou maior aplicabilidade das açôes locais, favorecendo o surgimento de experiências exitosas nos vários setores da saúde e nos seus diversos níveis de atenção, mediante processos de regionalização e hierarquização (FERLA; LEAL; PINHEIRO, 2006). No entanto, essas ações foram implementadas por procedimentos normativos, que tentam organizar o fluxo das pessoas via sistema, ocasionando um enrijecimento da atenção à saúde, ao se estruturar com base em um modelo piramidal de assistência (MATTOS, 2007).

Como evidenciado, os procedimentos burocráticos do sistema de referência e contrarreferência ocorrem de maneira engessada e rígida, sem possibilidade de flexibilização. Desse modo, a circulação dos usuários fica obstaculizada por inúmeros procedimentos que lhes dificultam os atendimentos. Trata-se de exigências formais segundo as quais consultas especializadas só podem ser marcadas se referenciadas por meio da rede básica de saúde. Tal exigência enrijece o acesso dos usuários aos serviços prestados.

O processo de referência e contrarreferência diz respeito aos procedimentos de encaminhamento verificados de maneira verticalizada entre os níveis de complexidade do sistema de saúde que ordena o fluxo dos pacientes tanto de cima para baixo quanto de baixo para cima, de maneira que as necessidades de assistência das pessoas sejam trabalhadas nos espaços tecnológicos adequados (CECÍLIO, 1997). 
Inicialmente, o projeto do SUS era constituir uma estrutura piramidal de acesso aos diversos níveis do serviço de saúde. No entanto, a realidade se mostra desorganizada, e o processo de adoecimento, do mesmo modo, não responde a uma suposta ordem do cosmos. Diante desta realidade, Cecílio (1997) reconhece ter-se instituído de forma espontânea várias portas de entrada no sistema, onde a atenção básica é uma delas, mas há também as urgências, as equipes de Saúde da Família e outras encontradas pelos próprios usuários na busca do cuidado. Assim, o autor sugere o modelo circular, o qual se associa à ideia de movimento e de várias alternativas de entrada e de saída. Um círculo não tem ponta, não possui hierarquia e funciona de forma horizontal, sem gradação de níveis hierárquicos verticais. Contudo, o sistema precisa funcionar de acordo com as necessidades de seus usuários, e não com base em forma preestabelecida, na qual os usuários é que têm de se encaixar.

Consoante verificar, o olhar sobre a micropolítica dos processos de trabalho em saúde possuui redes de muitas ligações e conexões. A característica principal desse sistema são as múltiplas entradas, a multiplicidade e heterogeneidade na sua composição, isto é, uma rede que se articula, sobretudo no plano do trabalho cotidiano, se realiza com fundamento em muitas articulaçôes, e convive com o diferente, é capaz de dar expressão às múltiplas facetas que compõem a paisagem do SUS, em especial no âmbito do rico e dinâmico lugar de trabalho de cada um. Essas redes são caracterizadas como rizomáticas, conceito inspirado no rizoma ${ }^{1}$ e utilizado para demonstrar as características de redes existentes no mundo da vida, e que serve para pensar no caso da saúde (DELEUZE; GUATTARI, 1995; FRANCO, 2006). É preciso, portanto, reconhecer a existência de um tipo de rede que se constitui sem modelo, que não parte de uma estrutura, pois se constrói em ato, com base no trabalho vivo de cada trabalhador e equipe, mediante fluxos de conexões entre si, na busca do cuidado em saúde, seja em encaminhamentos realizados, procedimentos partilhados, projetos terapêuticos que procuram consistência no trabalho multiprofissional.

É possível perceber a intensidade das redes e seu funcionamento nos serviços de saúde, tomando como foco a análise da micropolítica do processo de trabalho para o cuidado em saúde. Desta forma, uma rede funciona com base no trabalho das equipes de saúde, são os trabalhadores os operadores da rede. E eles acionam suas redes, instituídas ou não, a partir dos projetos terapêuticos 
pensados para resolver os problemas de saúde dos usuários. Logo, o projeto terapêutico é o disparador da rede, e assim não há uma rede a priori, mas construída em ato, sendo, pois, trabalho vivo dependente, como é característica do trabalho em saúde, segundo Merhy (2002). As redes atravessam equipes e equipamentos de saúde, podem se articular de uma unidade básica para emergência, ou desta para um hospital; enfim, os caminhos a serem percorridos são acionados sempre para cada caso, e pautados nas necessidades dos usuários e nos recursos disponíveis para o seu cuidado.

$\mathrm{Na}$ ótica de Franco (2006), as redes são inerentes ao processo de trabalho em saúde, ou seja, não há trabalho sem que se constitua uma rede em torno do seu objeto. Por conseguinte, a questão posta para reflexão é a característica da rede: se ela, por exemplo, funciona de forma harmônica, ou conflituosa; se há conexão de fluxos, ou a rede é fragmentada. Independentemente da resposta, o trabalho no âmbito da sua micropolitica, nos atos produtivos, é sempre em rede. As redes formadas dentro do sistema de saúde têm expressão no meio social, mediante diversos agenciamentos; elas propiciam o surgimento de novos modos de relação, constroem-se no meio social onde cada sujeito está inserido. Adaptam-se às novas possibilidades de atuação dos sujeitos no campo de produção da vida, produzem múltiplas conexões e fluxos construídos a partir de processos, que interligam os diversos atores, e criam linhas de contatos entre os agentes sociais, que são a fonte de produção da realidade.

Diferentemente do Modelo Circular, o Modelo Rizomático não tem limites em si, ou seja, opera de acordo com o tensionamento dos atores que o constituem. Não é previamente estruturado e se dá em consonância com as necessidades de ajuste. Cabe ressaltar: uma das referências para esta discussão são as novas formas de organização dos serviços de saúde mental, fruto da reestruturação do setor no Brasil.

\section{Organização dos serviços de saúde mental}

Para Alves (2001), um dos dispositivos estratégicos mais eficientes para a superação do modelo manicomial são os Centros de Atenção Psicossocial. Por serem comunitários, esses serviços estão inseridos em determinada cultura, num território definido, com dificuldades, problemas e potencialidades. São locus onde as crises precisam ser enfrentadas, crises oriundas de uma teia complexa 
de aspectos individuais, familiares e sociais. São serviços destinados a articular as ações de saúde mental em rede e junto à atenção básica (Programa Saúde da Família - PSF), ambulatórios, leitos de internação em hospitais gerais e ações de suporte e reabilitação psicossocial (ONOCKO-CAMPOS; FURTADO, 2006).

Os Caps subvertem a lógica da hierarquização e se organizam agregando os diferentes níveis de atenção à saúde em uma só unidade. Fazem, pois, surgir importantes questões na própria organização do SUS. Prestam atendimento especializado dos casos de transtornos mentais e são responsáveis pelo acompanhamento dos pacientes nas unidades de internação nos hospitais gerais. Podem atuar em nível de atenção primária, no acompanhamento e apoio matricial de casos nas Unidades Básicas de Saúde (UBS), perpassando, portanto, todos os níveis de complexidade da rede de saúde (ONOCKOCAMPOS; FURTADO, 2006).

Como proposto, o apoio matricial consiste num arranjo organizacional em saúde no qual uma equipe dispensa apoio especializado a outra, com suporte de profissionais dotados de maior habilidade em um dado conhecimento, possibilitando a construção de um projeto terapêutico singularizado para os usuários. Assim, esta ferramenta de trabalho subverte a lógica burocrática do encaminhamento das referências e contrarreferências, a qual, na maioria das vezes, costuma ser uma ferramenta de desresponsabilização dos profissionais em relação aos usuários. No apoio matricial em saúde mental, há a configuração da construção de um projeto terapêutico amplo, onde a equipe de referência não apenas está envolvida no caso, mas articula outros atores para a condução deste (CAMPOS, 1999).

Tais serviços devem estar interconectados com os demais serviços do sistema de saúde, evitando a fragmentação dos atendimentos. Centro de gravitação dos atendimentos em saúde mental, e o PSF, serviços de atendimento de saúde em geral, os Caps precisam estar articulados com vistas a facilitar o planejamento de açôes na respectiva área distrital de cobertura, principalmente no tocante às visitas domiciliares e às intervenções clínicas na rede de suporte social e de inter-relações pessoais significativas do usuário do serviço (VIEIRA FILHO; NÓBREGA, 2004).

Em países com sistemas de saúde descentralizados, o desenvolvimento de políticas de saúde mental deve enfatizar a comunicação entres os vários níveis de 
complexidade do sistema de saúde, trazendo a discussão dos modelos assistenciais em saúde para o campo da saúde mental, sobretudo em relação aos serviços alternativos ao modelo manicomial (DRAPER et al., 2009). Para tanto, tem-se como objetivo discutir as interações estabelecidas entre os níveis de complexidade do sistema de saúde na atenção à saúde mental e compreender a conformação da rede de atenção à saúde mental no município de Sobral-CE.

\section{Metodologia}

Trata-se de estudo do tipo qualitativo, cuja finalidade é a compreensão do conhecimento, buscando o sentido e o significado do fenômeno (MINAYO, 2007). Como citado, foi desenvolvido na Rede de Atenção Integral à Saúde Mental do município de Sobral-CE, cidade polo da macrorregião norte do Estado do Ceará detentora de uma população de 175.814 habitantes, subdivididos na sede (composta por bairros) e em distritos. Sobral é uma das cidades que incorporam o Pacto pela Vida e em Defesa do SUS, com ampla cobertura do PSF.

Da mencionada rede constam os seguintes serviços: Centro de Atenção Psicossocial (Caps-Geral), que atende à clientela com transtornos mentais; Centro de Atenção Psicossocial Álcool e Drogas (Caps-Ad), responsável pelo atendimento das pessoas com problemas atinentes ao uso abusivo de substâncias psicoativas; Serviço Residencial Terapêutico, local onde moram pessoas que perderam os vínculos familiares e sociais egressas do antigo manicômio da cidade; Unidade de Internação Psiquiátrica em Hospital Geral, que é referência tanto para os usuários do município de Sobral e como para os demais da Macrorregião Norte do Estado do Ceará; Clínica Médica em Hospital Geral, para os casos de desintoxicação moderada e grave; Ambulatório de Psiquiatria do Centro de Especialidades Médicas (CEM), referência para os casos de transtornos mentais da Macrorregiāo Norte, e a Terapia Comunitária realizada nos territórios.

Definiram-se os sujeitos da pesquisa pela saturação teórico-empírica e pela relevância das informações e das observações sugestivas de contribuiçõos significantes e adequadas ao delineamento do objeto em apreensão. Para conformar, os sujeitos foram selecionados em três grupos de informantes-chave: nove trabalhadores de saúde mental, dez usuários (clientes e familiares) e quatro coordenadores dos serviços, apresentados nos resultados, respectivamente, como trabalhador, usuário e coordenador. Para a conformação dos sujeitos, 
adotaram-se critérios de inclusão: trabalhadores com mais tempo de serviço na rede, pois acumularam mais experiência na rede; e trabalhadores envolvidos em ações de saúde mental em mais de um nível de atenção do sistema de saúde, pois proporcionariam uma visão dessas açôes e de como elas se configuram nos diversos espaços da rede.

Em relação aos usuários e familiares, utilizou-se como critério de inclusão para a entrevista aqueles que receberam cuidados de saúde mental nos mais diferentes níveis de atenção na rede, no intuito de observar de que maneira são implementadas essas ações do ponto de vista dos usuários e familiares. E como critério de exclusão, não se entrevistaram usuários internados na Unidade Psiquiátrica do Hospital Geral ou com dificuldades emocionais e cognitivas que impossibilitam sua participação.

Como técnicas e instrumentos de coleta de dados, optou-se a entrevista semiestruturada e a observação sistemática. E em consonância com o exigido, o projeto foi submetido à análise do Comitê de Ética em Pesquisa da Universidade Estadual do Ceará (UECE) e aprovado conforme processo no 07520905-5.

\section{Resultados}

\section{Porta de entrada}

Em Sobral, os serviços de saúde mental de possuem múltiplas "portas de entrada”. Desse modo, os usuários tanto podem ser referenciados pelas diversas unidades de saúde do município, como pelos diversos setores sociais; e ainda, por empresas privadas. Cada serviço de saúde mental se adapta com vistas a propiciar maior acesso às pessoas que dele necessitem.

No Caps-Geral há uma demanda organizada, com os encaminhamentos feitos a partir do apoio matricial ocorrido nas unidades de saúde da família, nível primário de atenção à saúde. $\mathrm{O}$ apoio matricial consiste em atividades de atenção e de educação permanente realizadas pelos profissionais dos serviços de saúde mental em parceria com os profissionais do Programa Saúde da Família. Entretanto, a forma organizacional do serviço de saúde mental Caps-Geral de Sobral, por meio dos encaminhamentos da atenção básica, não tem apenas a finalidade de organização do sistema de saúde em níveis hierárquicos. Cabelhe também promover apoio especializado aos serviços de atenção primária à saúde, possibilitando ampliar conhecimentos em abordagem, cuidados 
e encaminhamentos dos casos de transtornos mentais, como se observa empiricamente nos discursos convergentes, a seguir:

[...] nós trabalhamos com demanda organizada. A demanda é oriunda de encaminhamentos, que são realizados pelas preceptorias de psiquiatria, realizadas nos centros de saúde da família e também por pacientes egressos da ala de psiquiatria do hospital geral Dr. Estevam [...] alguns pacientes que não vão pra ala psiquiatra que vão pra clínica, mas algumas situações eles são encaminhados pra vim ao Caps [...] (Trabalhador 5).

[...] a porta de entrada é a estratégia de saúde da família [...] (Coordenador 3).

Conforme se percebe, o fluxo de organização do Caps-Geral se dá também de maneira hierarquizada, por meio de uma demanda organizada que parte da atenção primária e chega até o serviço especializado, por meio da referência e da contrarreferência, tal e como bem complementa a discurso do seguinte usuário:

[...] me deram um papel para mim apresentar aqui no Caps, aí passou uns dias aí eu vim aqui no Caps. Graças a Deus de lá pra cá tem dado tudo certo [...] (Usuário 5).

Em Sobral, nos finais de semana, os casos de urgência ou emergência em saúde mental são referenciados à Unidade de Internação Psiquiátrica em Hospital Geral (UIPHG), avaliados pelo plantonista clínico e depois submetidos a uma avaliação psiquiátrica, provavelmente ainda no final de semana, como bem destacam os discursos:

[...] fui direto pra internação, quando eu cheguei lá já tinha um lugar certo pra eu ficar [...] (Usuário 9).

[...] quando não o Caps já encaminha o paciente com prescrição feita, até laudo já vem preenchido de lá, tudo bem organizado, ou nos finais de semana, quando não tem, recebe a atenção do plantonista e pede uma avaliação do psiquiatra no outro dia [...] (Trabalhador 8).

Como mostram os discursos, os serviços viabilizam diversas formas de acesso aos cuidados necessários; assim, a população pode ser assistida, principalmente durante os fins de semana, quando os serviços de referência secundária Caps estão fechados.

[...] e tem um paciente internado na psiquiatria a gente mantém intercâmbio com os Caps, questão de prontuários, qual foi a última de depósito que foi administrada quando? [...] Isso já vem no prontuário [...] e também a gente busca outras informações enquanto o paciente esteja internado, fazer uma visita domiciliar, rastrear melhor o que foi que houve, saber se está tomando a medicação mesmo direito, que às vezes não está aderindo bem ao tratamento e assim tem esse intercâmbio [...] (Coordenador 5). 
O discurso demonstra a construção cotidiana de relações em rede,

formadas entre hospital, Caps, domicílio do usuário, e neste caso específico, para acompanhamento do usuário. Nota-se uma atenção especial quanto à administração de medicamentos, um esforço de controlar este quesito, ao admitir que o "não tomar a medicação" significa "não adesão ao tratamento". Vale ressaltar, porém: aparece nesta fala um serviço que dispensa especial atenção a determinado quesito do projeto terapêutico, a medicação, e o que seriam os outros dispositivos de cuidado não contemplados aqui? A "não adesão" ao medicamento pode ser uma forma do usuário de escapar de certos efeitos colaterais, sabidamente danosos - por exemplo, para sua vida afetiva. Este ato deve ser analisado na perspectiva do usuário e os trabalhadores devem estar dispostos a negociar o projeto terapêutico, e não admitir de pronto como uma negatividade o fato de não tomar a medicação.

Consoante discute Franco (2006), todo cuidado em saúde sempre se produz em rede, por meio de articulaçôes entre os serviços de saúde nos seus diversos níveis, entre as equipes, os saberes, as práticas e as subjetividades, remetendo à ideia de imanência e de interdependência. Assim, existe cuidado compartilhado quando há entre trabalhadores, e destes com usuários, o compartilhamento de saberes e fazeres, o encontro, mútuo reconhecimento, e intercessão do saber científico com o saber da experimentação da vida, popular, que entrelaça as diversas racionalidades e a dimensão sensível e afetiva. Cuidado compartilhado é uma forma de fazer, e neste sentido é uma tecnologia de trabalho em saúde.

A rede conformada entre os serviços, o domicílio e a comunidade deve servir para a construção compartilhada do cuidado, incluindo a gestão autônoma de medicamentos (PASSOS; CARVALHO; MAGGI, 2012). Tal fato seria importante, mas, como fica demonstrado, esse serviço não inclui o usuário nessa negociação. No entanto, os extratos de entrevistas a seguir demonstraram a constituição e operação de redes rizomáticas no âmbito dos serviços, onde os trabalhadores operam seu processo de trabalho mediante conexão entre serviços, sendo eles próprios mediadores e propulsores dos fluxos por onde o usuário vai caminhar na busca da solução para seu problema de saúde. E esta construção se dá em ato, onde o principal recurso é a liberdade proporcionada pelo trabalho vivo, ou seja, é no exato momento de produção que as redes se conectam e 
constituem as linhas de cuidado necessárias para aquele caso específico, isto é, as redes "rizomáticas" serão sempre singulares.

[...] só que a gente tem algumas exceções, a gente tem um diálogo muito forte com a Grendene [...] algumas situações que são verificadas pelo médico do trabalho ou pelo setor de serviço social da empresa que tem risco, que são pacientes com, mas nem só pacientes do Caps, mas pessoas que procuram esses profissionais relatam ideação suicida, ou eles percebem que é uma depressão que já não é algo leve, eles já encaminham, ligam pra gente, encaminham e a gente já atende sem passar pelo trâmite da atenção básica [...] (Trabalhador 5).

[...] nossa demanda ela chega na rede, não só espontaneamente direto ao serviço [...] ela chega também através dos equipamentos que compõem a rede [...] o hospital [...] nós temos encaminhamentos das unidades básicas de saúde [...] de outros equipamentos que não compõem a rede [...] de programas sociais daqui do município, como por exemplo conselho tutelar, um CREAS, CRASS [...] eu citaria também o Juizado, o fórum [...] (Trabalhador 1).

[...] ela tava usando droga, na escola ela teve baixo rendimento escolar, e eu fui pedir ajuda, até o S.O.S. criança, onde ela foi colocada no abrigo domiciliar de Sobral, e aí ela foi encaminhada pra cá [...] através do abrigo domiciliar [...] (Usuário 1).

Ainda como essas narrativas sugerem, não há demanda organizada, e nem a possibilidade de ordená-la, porque o mundo da vida não tem uma ordem específica, ele se produz em um emaranhado de relações, afetos, encontros. Por esse motivo, a ação cotidiana dos trabalhadores, a micropolítica do processo de trabalho vai demonstrar uma diversidade de ações, a necessidade de que os trabalhadores sejam inventivos e criativos para a produção do cuidado. A construção de redes revela um trabalhador ativo, implicado e construtor de linhas de cuidado que também não obedecem a uma ordem na sua singularidade; ela se forma para atender à necessidade de cuidado e a um projeto terapêutico igualmente singular.

Como se pôde observar neste estudo, os serviços de saúde mental de Sobral não se consolidam como modelo piramidal por meio dos procedimentos de referência e contrarreferência, pois apresentam outras possibilidades de acesso aos serviços e procuram se adequar à demanda apresentada. Inexiste rigidez quanto à "porta de entrada", ou seja, há uma quebra da lógica verticalizada do sistema de saúde. Desse modo, os encaminhamentos podem vir tanto do nível primário de atenção quanto dos hospitais de referência. Os clientes vêm dos mais diversos setores sociais, bem como de quaisquer níveis de complexidade do sistema de saúde, como exemplificam os discursos a seguir: 
[...] peguei uma depressão na empresa de calçados e fui encaminhado para o Caps-

-Geral [...] (Usuário 3).

[...] Fui no hospital, conversei com a assistente social de lá e ela foi e me encaminhou pra cá [...] (Usuário 8).

[...] se é um caso grave que a pessoa precisa de um atendimento, [...] ou de populares que vê uma pessoa desorganizada que está perambulando pela rua e aí nos comunica e a gente faz a busca ativa nessa situação [...] (Trabalhador 5).

Segundo se percebe, a atenção à saúde mental na rede de Sobral possui várias "portas de entrada" para quem precisa de cuidados, e neste caso específico demonstra atuar de maneira horizontalizada, aproximando-se de uma articulação em rede próxima da ideia de um modelo rizomático, o qual se caracteriza, principalmente, como um sistema de múltiplas entradas, conforme já discutido. Mas a rede não é única, nem se realiza de uma só forma. Portanto, há vários arranjos na constitução das redes de cuidado, que podem ser formais, burocráticas e também fluidas, desenvolvidas pelas equipes na micropolítica do seu trabalho cotidiano. Ademais, os dois tipos podem conviver no mesmo tempo e espaço, e são acionados de acordo com situaçôes singulares vividas pelos trabalhadores, onde estes acionam as redes pautados pelas necessidades dos usuários.

\section{Atenção em rede}

A organização dos serviços de saúde mental de Sobral se aproxima de um tipo em que há espaços para a constituição de redes mediante de conexões e fluxos produzidos pelos próprios trabalhadores, no cuidado cotidiano, e dentro de um critério de liberdade que constitui o trabalho vivo em ato. No entanto, como é preciso reconhecer, há vários tipos de redes presentes no serviço, ao mesmo tempo. Esta multiplicidade é própria da saúde, desde que analisada com foco na micropolítica do trabalho das equipes.

Segundo observado, diferentes serviços compõem a saúde mental no município nos diversos níveis de complexidade do sistema de saúde, assim como equipes multiprofissionais que empreendem grande poder de articulação dos serviços entre si e também deste com os demais setores sociais, adequando-se às necessidades dos usuários demandantes de assistência. Esta organização rompe com a ideia de modelo único, sem poder de flexibilização das ações, limitando a assistência e organizando a demanda de acordo com as necessidades do sistema e não de acordo com as necessidades dos usuários. 
Como mencionado anteriormente, o processo de trabalho em saúde opera em rede, pois parte da constatação segundo a relação dos trabalhadores entre si, e deles com usuários, possibilitando a interlocução entre os atores na construção de redes na produção do cuidado. No entanto, a construção desta rede pode estagnar e se enrijecer pelos procedimentos burocráticos e normativos, mediante regras preestabelecidas que repetem velhos métodos de gerir o cuidado (FRANCO, 2006), ou podem romper a norma estabelecida, e em ato, constituir novos fluxos que atendem aos usuários.

Em Sobral, a relação entre os serviços de saúde mental secundários, os Caps e a Unidade de Internação Psiquiátrica é bem estreita, assim como a relação com as unidades do Programa Saúde da Família. A intervenção de saúde mental nas UBS surgiu no município através dos deslocamentos, inicialmente, dos psiquiatras para a realização de algum tipo de apoio. Tal atividade que se denominou num primeiro momento de "preceptoria de psiquiatria", vinculada à formação de residentes multiprofissionais (médicos ou não) em Saúde da Família, e posteriormente absorveu a nomenclatura, reconhecida nacionalmente em Saúde Coletiva, de apoio matricial (TÓFOLI, 2007).

Desta forma, os profissionais que trabalham nos Caps também atuam na unidade de internação e implementam o apoio matricial nos postos de saúde do município, facultando um acompanhamento mais próximo dos casos e facilitando a comunicação entre os serviços. Complementam, assim, a ideia discutida segundo a qual o processo de trabalho em rede se constrói com base na desconstrução dos modelos preestabelecidos e normativos, engessados em funçôes cristalizadas. Essa ideia é complementada pelos discursos a seguir:

[...] Como a equipe de internação é a que compõe os outros serviços, então é um processo bem menos burocrático, só precisa saber se tem vaga ou não [...] (Coordenador 2).

[...] e uma coisa que facilita muito é o fato de ter profissionais num serviço que frequentam o outro. Isso ajuda muito a questão da comunicação da relação do paciente com a equipe $[. .$.$] (Trabalhador 6).$

[...] como a gente tem a unidade psiquiátrica e tem a clínica, tem um médico que trabalha com a gente que trabalha todos os dias no hospital, ele é que faz esta ponte [...] como a gente tem dois assistentes sociais, um no Caps-Ad e outro no Caps-Geral, que estão uma vez por semana no hospital, casos que precisem de alguma resolução do serviço social [...] a gente tenta fazer de toda forma para que assim que o paciente saía do hospital seja encaminhado pra cá. Como a gente dá plantão, tem todo um envolvimento, não é só o médico que está lá, é uma equipe toda [...] (Coordenador 1). 
[...] a comunicação entre UBS e os serviços de referência Caps e Caps-Ad a maioria é

feita através da preceptoria de Psiquiatria que agora, há um tempo já, não está indo só o psiquiatra em alguns centros de saúde da família, já vai o psiquiatra e outro profissional, como terapeuta ocupacional, psicólogo [...] (Trabalhador 5).

Segundo essas falas, os trabalhadores demonstram importante movimentação entre si, e entre serviços por onde eles andam no seu processo de trabalho. Evidencia-se nesses movimentos o aproveitamento da mobilidade de cada um para formar suas redes de trabalho e linhas de cuidado. Nesse contexto, não há uma organização da demanda a priori, ou uma ordem para sua resolução, mas ela é absorvida, atendida, encaminhada nos fluxos formados pelos trabalhadores, no seu movimento nômade por dentro dos serviços de saúde. Os dados vão revelando o elevado potencial dos trabalhadores para o cuidado, o alto grau de controle sobre seu próprio processo de trabalho e a capacidade de governarem esse espaço que é do seu domínio: o da produção do cuidado.

Como exposto, os serviços de saúde mental se articulam entre si e também com os demais componentes da rede de serviços integrantes do sistema de saúde. Rompem com a ideia de hierarquização de organização dos serviços de saúde e, assim, propiciam a circulação de profissionais pelos vários serviços da rede, atuando nos mais diferentes níveis de complexidade. Ademais, possibilitam a assistência dos seus usuários ao mesmo tempo nos mais diversos níveis de complexidade do sistema de saúde. Essa proposta de organização é qualificada por Tófoli (2007) como uma "des-hierarquização". Os profissionais estão em vários serviços de saúde mental, nos múltiplos níveis de complexidade: Unidade de Internação Hospitalar, Caps e PSF. Pode-se ainda empiricamente comprovar que a "des-hierarquização" proposta pelo autor também é reforçada no presente estudo quando se nota a circulação dos usuários de saúde mental em níveis de complexidade diferentes ao mesmo tempo, desconstruindo a ideia enrijecida do modelo piramidal de atenção à saúde, onde o indivíduo só poderia estar em um nível hierárquico por vez.

Neste âmbito, o fato de os profissionais poderem circular pelos serviços viabiliza a construção de novas articulações e fluxos conectivos, além da experimentação de novos processos de trabalho, não se cristalizando em determinadas funçôes específicas e, ainda: os profissionais responsáveis pelo apoio matricial em saúde mental na atenção primária têm a possibilidade de observar os usuários no seu território e perceber comportamentos não perceptíveis, por exemplo, numa internação ou num acompanhamento ambulatorial. 
Conforme consta em estudos, a prática terapêutica no território se modula de maneira diferente da do consultório, construindo um trabalho junto à população local e nos serviços comunitários. Com a interconexão entre os serviços de saúde mental e os PSFs, evita-se a fragmentação dos atendimentos e facilita-se o planejamento das ações no território, tais como os atendimentos domiciliares e as intervençôes clínicas na rede pessoal significativa dos sujeitos (VIEIRA FILHO; NÓBREGA, 2004). Por conseguinte, as novas formas organizacionais em saúde mental diferem das antigas estruturas dominantes quando operam com o foco na autonomia dos usuários, na estreita relação entre os usuários e trabalhadores e na integração dos serviços de saúde mental com a comunidade (GRANT, 2010).

Assim, esta ação matricial em saúde mental na atenção básica propicia a construção de um projeto terapêutico que não se limita às fronteiras de um dado serviço, mas é diluído em variadas instâncias, articulado por uma equipe de referência, e mobiliza diversos atores para lidar com o andamento do caso. Possibilita um cardápio amplo de estratégias que enriquece o projeto terapêutico e viabiliza a articulação de redes de cuidados, através dos profissionais integrantes das equipes de matriciamento. Portanto, os serviços de saúde mental podem explorar recursos comunitários outros que não apenas as ferramentas clínicas dos ambulatórios, sobretudo ao discutir com as equipes de saúde da família estratégias que perpassem os muitos níveis de atenção do sistema de saúde, criando novas linhas de cuidado destinadas a atender à demanda do usuário.

Destaca-se pois, o fato de essa junção de serviços de saúde mental se autointitular "Rede de Atenção Integral à Saúde Mental de Sobral-CE". Isto poderia suscitar a ideia de uma rede dissociada do restante da rede de serviços componentes do sistema de saúde, porém não é o que se identifica empiricamente nos discursos convergentes a seguir:

[...] a unidade de saúde quer discutir um caso, vai a equipe do Caps até eles ou a gente vai discutir um caso aqui no Caps, chama a equipe de saúde da família pra vim discutir conosco [...] (Trabalhador 5).

[...] vai estar circulando dentro dessa rede, e na rede entram tanto os Caps, quanto o hospital como a atenção básica, como, por exemplo, ele (o paciente) pode estar frequentando os três níveis de atenção dentro dessa rede [...] Ele pode ser internado num período e ficar no Caps outro período, pode dentro desse mesmo período estar no Caps e na atenção básica [...] participando da terapia comunitária que acontece na atenção básica, participando da massoterapia, ou sendo acompanhado pelo psiquiatra lá na atenção básica e no Caps pelo psicólogo [...] então ele vai estar circulando dentro dessa rede, dependendo das necessidades dele [...] (Trabalhador 9). 
[...] Passei primeiro por aqui e daqui eles me botaram pra lá [...] Da outra vez foi lá

da clínica (ambulatório de DST), que o médico psiquiatra me levou pra lá também [...] de lá ele já me encaminhou pra lá (pro hospital) quando eu passei uns dias lá e saí bem melhor [...] (Usuário 9).

Pode-se verificar, sobretudo na fala do "trabalhador 9", a diversidade de dispositivos terapêuticos ofertados pela rede. Isto mais uma vez corrobora a afirmação feita anteriormente, qual seja, os projetos terapêuticos não precisam ficar centrados na ação medicamentosa. É possível negociar com o próprio usuário a administração ou não, ou mesmo, diferentes dosagens de medicamentos, substituindo-os por outros recursos como os citados: massoterapia, terapia comunitária, inserção em grupos comunitários, etc [...] Percebe-se, então, certo paradoxo na rede, que tem ofertas diversificadas e ao mesmo tempo mantém a centralidade na medicação para certos casos. Urge os trabalhadores ficarem mais atentos às negativas dos usuários para o uso de certos medicamentos e buscarem fazer uma escuta desse fato, criando outras possibilidades de cuidado e renegociando seus projetos terapêuticos.

Ainda como as falas vão demonstrar, há só uma capilaridade no atendimento dos usuários entre os serviços componentes da atenção em saúde mental, e também com os outros serviços de saúde em seus diversos níveis de complexidade. A produção do cuidado em saúde mental fundamentada no acolhimento, no vínculo e na responsabilização requer o enfrentamento dos problemas em relação ao modo de funcionamento dos serviços substitutivos e da rede de saúde de uma forma geral (DIMENSTEIN et al., 2010).

Como se depreende, a atenção à saúde mental em Sobral aproxima-se de um modelo des-hierarquizado que viabiliza o cuidado integral dos seus usuários mediante articulação tanto dos serviços entre si quanto dos serviços de saúde mental com o restante da rede assistencial de saúde. Consequentemente, possibilita articulações com os múltiplos setores da sociedade e ajuda a desconstruir a ideia segundo a qual a pessoa com transtorno mental precisa ser cuidada apenas num espaço restrito a ela (QUINDERÉ; JORGE, 2010). A subversão da lógica da hierarquização é efetivada pelos Caps, e estes, ao se estruturarem como equipamentos-síntese, agregam os diferentes níveis de atenção em uma só unidade. Desse modo, fazem emergir relevantes questôes e debates no âmbito da própria organização do SUS (ONOCKO-CAMPOS; FURTADO, 2006). 
Assim, a articulação dos serviços de saúde mental em rede horizontalizada propicia uma interlocução mais profunda entre serviços de saúde, ao promover maior capilaridade das açōes em saúde mental no território e se articular com outros setores sociais. Desconstrói, pois, a lógica organizacional-burocrática expressa na ideia hierárquica, de referência e contrarreferência, muito presente nas redes de serviços, facultando várias opções de "portas de entrada" e redes singulares construídas pelos próprios trabalhadores. Favorece, então, o trânsito dos profissionais da rede de atenção por meio dos diversos níveis de complexidade do sistema de saúde, permitindo ao usuário estar, de acordo com seu projeto terapêutico, em vários níveis de complexidade e até mesmo em espaços comunitários fora da rede de serviços ao mesmo tempo. Logo os serviços podem se revelar agenciadores das açôes de saúde mental.

\section{Considerações finais}

Conforme o estudo demonstrou, os serviços de saúde mental em Sobral convivem com diferentes arranjos em rede. Ao se tomar como foco a micropolítica do processo de trabalho, na produção do cuidado, percebe-se o convívio de modos mais formais e burocráticos de ação, atividades que se parecem com a ideia de sistema em círculo, e redes construídas em ato, pela força e liberdade do trabalho vivo, buscando cumprir o projeto terapêutico na sua singularidade. Estas últimas, as redes rizomáticas, têm se constituído no cotidiano das práticas das equipes de trabalhadores de saúde mental, conforme mostra o estudo, embora se possa identificar a presença das demais.

Demonstra ainda diversidade de dispositivos de cuidado existentes na rede, o que possibilita a negociação de projetos terapêuticos menos medicalizantes, apesar de permanecer uma atenção especial dos trabalhadores quanto à centralidade da administração da medicação. Este é o paradoxo observado. Há uma grande mobilidade dos trabalhadores na rede, circulado entre vários e diversos equipamentos de saúde. Isto favorece as conecçôes e fluxos entre equipes na construção das linhas de cuidado.

Os fluxos de conexão considerados como modo de funcionamento das redes rizomáticas operam na saúde mental por força da ação dos trabalhadores, os quais têm por base a ideia segundo qual todos são protagonistas no processo de 
cuidado, e, assim, os movimentos são partilhados e articulados entre si. $\mathrm{O}$ estudo

reforça a necessidade de se avaliar os serviços de saúde mental, na perspectiva dos arranjos de trabalho existentes, no âmbito da sua micropolítica. ${ }^{2}$

\section{Referências}

ALVES, D. S. Integralidade nas políticas de saúde mental. In: PINHEIRO, R.; MATTOS, R. A. Os sentidos da integralidade na atenção e no cuidado à saúde. Rio de Janeiro: Cepesc, 2001. p. 167-176.

BAREMBLITT, G. Compêndio de análise institucional e outras correntes. Rio de Janeiro: Rosa dos Tempos, 1998.

CAMPOS, G. W. S. Equipes de referência e apoio especializado matricial: um ensaio sobre a reorganização do trabalho em saúde. Rev Ciênc. Saúde Coletiva, Rio de Janeiro, v. 4, n. 2, p. 393-403, 1999.

CECÍLIO, L. C. O. Modelos tecno-assistenciais em saúde: da pirâmide ao círculo, uma possibilidade a ser explorada. Cad. Saúde Pública. Rio de Janeiro, v.13, n. 3, p. 469-478, 1997. DELEUSE, G.; GUATTARI, F. Mil Platôs: capitalismo e esquizofrenia. São Paulo: Editora 34, 1995.

DIMENSTEIN, M. et al. Estratégia da Atenção Psicossocial e participação da família no cuidado em saúde mental. Physis Revista de Saúde Coletiva. Rio de Janeiro, v. 20, n. 4, p. 1209-1226, 2010.

DRAPER, C. E. et al. Mental health policy in South Africa: development process and content. Health Policy and Planning, n. 24, p. 342-356, 2009.

FERLA, A. A.; LEAL, M. B.; PINHEIRO R. Um olhar sobre as práticas avaliativas em descentralização do sistema de saúde: construindo uma abordagem analítica para atuação em rede. In: PINHEIRO, R.; MATTOS, R. A. (Orgs.). Gestão em redes: práticas de avaliação, formação e participação na saúde. Rio de Janeiro: Cepesc, 2006. p. 35-60.

FRANCO, T. B. As redes na micropolítica do processo de trabalho em saúde. In: PINHEIRO, R.; MATTOS, R. A. (Org.). Gestão em Redes: práticas de avaliação, formação e participação na saúde. Rio de Janeiro: Cepesc, 2006. p. 459-474.

GRANT, J. G. Embracing an emerging structure in community mental health services: hope, respect, and affection. Qualitative Social Work, v. 9, n. 1, p. 53-72, 2010.

HARTZ, Z. M. A.; CONTANDRIOPOULOS A. P. Integralidade da atenção e integração de serviços de saúde: desafios para avaliar a implantação de um "sistema sem muros". Cad. Saúde Pública. Rio de Janeiro, v. 20, sup 2, p. 5.331-5.336, 2004. 
MATTOS, R. A. Repensando a organização da rede de serviços de saúde a partir do princípio da integralidade. In: PINHEIRO, R.; MATTOS, R. A. (Org.). Razóes públicas para a integralidade em saúde: o cuidado como um valor. Rio de Janeiro: Cepesc, 2007. p. 369-383.

MERHY, E. E. Em busca do tempo perdido: a micropolítica do trabalho vivo em saúde. In MERHY, E. E.; ONOCKO, R. (Orgs.). Agir em saúde: um desafio para o público. São Paulo: Hucitec, 1997. p. 71-112.

MINAYO, M. C. S. O desafio do conhecimento: pesquisa qualitativa em saúde. 10. ed. São Paulo: Hucitec, 2007.

ONOCKO-CAMPOS, R. T.; FURTADO, J. P. Entre a saúde coletiva e a saúde mental: um instrumento metodológico para avaliação de rede de Centros de Atenção Psicossocial (CAPS) do Sistema Único de Saúde. Cad. Saúde Pública. Rio de Janeiro, v. 22, n.5, p. 10531062, 2006.

PASSOS, E.; CARVALHO, S. V.; MAGGI, P. M.A. Experiência de autonomia compartilhada na Saúde Mental: O "Manejo Cogestivo" na Gestão Autônoma da Medicação. Pesquisas e Práticas Psicossociais, São João del-Rei, v. 7, n. 2, p. 269-278, jul-dez 2012.

QUINDERÉ, P. H. D.; JORGE, M. S. B. (Des) Construção do Modelo Assistencial em Saúde Mental na Composição das Práticas e dos Serviços. Saúde Soc., São Paulo, v. 19, n. 3, p. 569-583, 2010.

TÓFOLI, L. F. Desinstitucionalização e integralidade no sertão cearense. In: PINHEIRO, R. et al. (Org.). Desinstitucionalização da saúde mental: contribuições para estudos avaliativos. Rio de Janeiro: Cepesc, 2007. p. 225-238.

VIEIRA FILHO, N. G.; NÓBREGA, S. M. A atenção psicossocial em saúde mental: contribuição teórica para o trabalho terapêutico em rede social. Rev. Estudos de Psicologia. Natal, v. 9, n. 2, p. 373-379, 2004.

\section{Notas}

${ }^{1}$ Rizoma é um vegetal de tipo tubérculo, que cresce subterrâneo (horizontalmente), mas muito próximo à superfície, e que se compõe essencialmente de uma raiz. Quando o exemplar alcança grandes proporçôes, é difícil saber quais são seus limites externos; no seu interior, o complexo, digamos, radicular, está composto por células que não têm membrana, e que só podem ser supostas como unidades porque têm núcleos ao redor dos quais se distribuem trocas metabólicas e áreas energéticas. Então, pelo menos no sentido tradicional, o rizoma não tem limites internos que o compartimentalizem. Aquilo que circula nesse interior circula em "toda e qualquer" direção, sem obstáculos morfologicamente materiais que o impeçam (BAREMBLITT, 1998, p. 58).

${ }^{2}$ P.H. Quinderé e M.S. Jorge realizaram análise e interpretação dos dados e redação do artigo. T.B. Franco realizou a revisão crítica do conteúdo intelectual do artigo. 


\section{Network for Psychosocial Care: what is the place of mental health?}

The Brazilian Health Reform provided greater applicability of local actions, favoring the emergence of successful experiences in various sectors of healthcare . One of these was the creation of Centers for Psychosocial Care (CAPS), which subvert the logic of hierarchy of the health system and are organized joining all different levels of health care. This study aimed to discuss the interactions established between the levels of complexity of the health system in mental health and understand the conformation of the mental health system in the city of Sobral, state of Ceara, Brazil. This is a qualitative study, conducted at the Comprehensive Care Network Mental Health in that municipality. The results showed that the mental health services in Sobral live with different networking arrangements, operating by several care devices that enable the negotiation of therapeutic projects less medicalized, although there is evidence of special attention to the centrality of workers as medication administration. There is great labor mobility in the network, circling the various health facilities, which favors the connections and flows between teams in the construction of lines of care. Connection flows, considered as a mode of operation of rhizomatic networks, operate on mental health under the workers' action, based on the idea that all are protagonists in the care process, and so the movements are shared and articulated between them.

> Key words: mental health care; community mental health services; integral health care; health care levels. 